удк 519.863

DOI: https://doi.org/10.32851/2708-0366/2021.8.11

Дебела I.M.

кандидат сільськогосподарських наук, доцент, Херсонський державний аграрно-економічний університет

Debela Iryna

Kherson State Agrarian and Economic University ORCID: https://orcid.org/0000-0001-7990-4202

\title{
БАЙЄСОВСЬКИЙ МЕТОД ОЦІНКИ АЛЬТЕРНАТИВНИХ РІШЕНЬ
}

\section{BAYESIAN METHOD OF EVALUATING ALTERNATIVE SOLUTIONS}

Більшість сучасних економіко-математичних моделей є багатокритеріальними оптимізаційними динамічними системами з переважно стохастичними параметрами. Математичні моделі ичи систем складні, пошук оптимального управління неоднозначний як за критеріями оптимальності, так $і$ за вибором методів очінювання вибраних альтернатив. Обмеженість вибіркових даних, випадковий характер параметрів моделі є характерними рисами прогностичних моделей економіки, відповідно, застосування до них методів класичної асимптотичної теорії необтрунтоване та неефективне. Байєсовський підхід розглядає випадковість як внутрішню природну властивість реального об 'єкта або процесу з урахуванням неперервних випадкових змін самого об' єкта як цілісної системи через вплив навколишнього середовища. Оиінками моделі вважають невипадкові статистичні характеристики, які досить близько апроксимують статистику випадкового параметра, тому під час практичного застосування дослідник працює з моделлю, щзо має детерміновані коефіцієнти. Метою дослідження є алгоритмізація процедури байєсовського очінювання альтернативних рішень.

Ключові слова: метод Байєса, альтернатива, стан природи, апріорні ймовірності, апостеріорні ймовірності, математична модель.

Большинство современных экономико-математических моделей являются многокритериальными оптимизационными динамическими системами с преимущественно стохастическими параметрами. Математические модели этих систем сложные, поиск оптимального управления неоднозначный как по критериям оптимальности, так и по выбору методов оченивания избранных альтернатив. Ограниченность выборочных данных, случайный характер параметров модели являются характерными чертами прогностических моделей экономики, соответственно, применение к ним методов классической асимптотической теории необоснованно и неэффективно. Байесовский подход рассматривает случайность как внутреннее естественное свойство реального объекта или процесса с учетом непрерывных случайных изменений самого объекта как иелостной системь из-за влияния окруюающей среды. Оиенками модели считают неслучайные статистические характеристики, которье достаточно близко аппроксимируют статистику случайного параметра, поэтому при практическом применении исследователь работает с моделью, имеющей детерминированные коэффициентьл. Целью исследования является алгоритмизация прочедуры байесовского оченивания альтернативных решений.

Ключевые слова: метод Байеса, альтернатива, состояние природы, априорные вероятности, апостериорные вероятность, математическая модель.

Most modern economic and mathematical models are multicriteria optimization dynamic systems with predominantly stochastic parameters. The mathematical models of these systems are complex; the search for optimal control is ambiguous, both in terms of optimality criteria and in the choice of methods for evaluating selected alternatives. The limited sample data, the random nature of the model parameters are a characteristic feature of predictive models of the economy, respectively, the application of the methods of the classical asymptotic theory to them is not justified and not effective. The Bayesian approach considers randomness as an intrinsic property of a real object, or process, taking into account the continuous random changes of the object itself, as an integral system, due to the influence of the environment. The estimates 
of the model will not be random statistical characteristics that approximate the statistics of a random parameter rather closely. Therefore, in practical application, the researcher works with a model that has deterministic coefficients. The aim of the research is the algorithmization of the Bayesian estimation procedure for alternative solutions. Modeling is described as a step-by-step process that begins with the identification of empirical patterns of development of the objectobject system, analysis of external and internal factors, their relationships, and trends in dynamic environmental change. The next step is a theoretical assumption about the internal logical model of behavior of the object under study, the presence of typical relationships between structural parts and the influence of the environment - the state of nature. The solution of such problems can be found by searching for elements of a set of alternatives, each of which with some probability can be the optimal solution depending on random states of nature. The Bayesian method of probabilistic estimation of alternatives allows building a rather simple and effective model of decision-making for the formed set of a priori features - states of nature. The choice of methods for forming the distribution of a priori probabilities is not limited to statistical algorithms, for economic and mathematical models the easiest to implement is the method of expert estimates. A significant advantage of the Bayesian method is the ability to adjust and refine the initial values of a priori probabilities, in the event of new information about the object of study.

Key words: Bayesian method, alternative, state of nature, prior probability, posterior probability, mathematical model.

Постановка проблеми. Більшість сучасних економічних систем функціонують як багатокритеріальні оптимізаційні динамічні системи з частково або повністю стохастичними параметрами. Багатокритеріальний характер визначається необхідністю одночасної оцінки стратегічних альтернатив за багатьма показниками, частина 3 яких суб'єктивна, не має кількісного еталону вимірювання. Математичні моделі цих систем складні, пошук оптимального управління неоднозначний як за критеріями оптимальності, так і за статистичними оцінками вибраних альтернатив. Крім того, існує невизначеність у повноті сформованого списку можливих альтернатив. Завжди можна припустити, що не всі варіанти можливих рішень були досліджені. Такі труднощі роблять процес моделювання прийняття рішення досить непростим та витратним. Іноді побудова математичної моделі досліджуваної системи, процесу або явища недоцільна через неможливість формалізації якісних характеристик, непрогнозований стохастичний характер досліджуваних процесів. Застосування допустимих обмежень, що спрощує математичний апарат окремих економіко-математичних моделей, значно зменшує ступінь адекватності моделі та їі статистичну значимість. Крім того, забезпечити адекватність математичної моделі, побудованої лише на емпіричних даних, без обгрунтованих, «розумних» теоретичних припущень досить проблематично.

3 розвитком економіко-математичних досліджень, появою нових моделей «змішаного типу» відбувається процес інтеграції вже наявних моделей у конструктивно нові комплексні моделі, параметрична база яких формується як результат статистичного аналізу кількісних факторів та якісного аналізу неформалізованих, лінгвістичних змінних. Проблема ефективного управління такими системами трансформується в проблему прийняття узгоджених рішень як компромісу між ендогенними та екзогенними цілями системи [1, с. 178; 2, с. 45-47] та потребує постійного дослідження.

Аналіз останніх досліджень і публікацій. Концептуальні аспекти моделювання економічних процесів досліджували Г.І. Великоіваненко, С.М. Братушко, С.С. Павліщенко, С.А. Нужна. Математичні основи методу динамічного статистичного моделювання економічних процесів описали О.І. Чумаченко, В.І. Балута, Д.Н. Шульц. Класифікацію ризиків та байєсовський підхід до їх аналізу вивчали П.І. Бідюк, А.С. Борисевич, М.3. Згуровський. Формалізація процесу прийняття рішення в умовах багатокритеріальної оптимізації та інтервальної невизначеності є предметом дослідження Е.Г. Петрова, В.В. Крючковського. Байєсовський підхід в економетриці описаний у статті Л.О. Бабешко. Застосування методу Байєса в економіці є предметом дослідження Н.В. Кузнєцової, М.В. Андрєєва. 
Формулювання цілей статті. Рішення в умовах стохастичної невизначеності параметрів моделі можна знайти шляхом перебору елементів множини альтернатив, кожна 3 яких 3 деякою ймовірністю може бути оптимальним рішенням [3, с. 199]. Оцінка вартості альтернативних рішень в умовах параметричної невизначеності та ризиків різної природи описується ймовірнісним розподілом. Традиційно оцінкою вартості альтернатив слугує модифікований критерій очікуваного значення. Сутність модифікованого критерія очікуваного значення грунтується на припущенні, що очікуваний прибуток (витрати) кожної альтернативи є випадковою величиною [4, с. 524-526]. Розподіл імовірностей, що застосовується під час формулювання критерія очікуваного значення, отримують, як правило, шляхом модифікації імовірностей за допомогою накопиченої раніше або поточної статистичної інформації, даних вибірки чи експерименту. Таку модифікацію імовірностей називають апостеріорною, або байєсовським підходом. Однією з ключових переваг байєсовського підходу є використання наявних початкових даних щодо параметрів моделі у вигляді апріорної ймовірності, або диференційної функції розподілу ймовірності. Потім апріорні ймовірності корегуються за допомогою отриманих вибіркових даних, які знаходять своє відображення у вигляді апостеріорного розподілу оцінок параметрів або змінних моделі [5, с. 40-57]. Такий підхід дає змогу точніше оцінювати моделі, отримувати хороші результати у випадках, коли використання класичних методів неправильне (вибірки малого об'єму). Обмеженість вибіркових даних, характерна риса прогностичних моделей економіки, відповідно, застосування до них методів класичної асимптотичної теорії необгрунтовані та статистично неефективні. Байєсовські методи відрізняються від класичних іншим підходом до інтерпретації істинних параметрів моделі. Класичний підхід виходить із того, що справжні параметри - це не випадкові величини, а апроксимуючі їх оцінки випадкові, оскільки є функціями спостережень, тобто випадковими процесами [6, с. 46-57]. Байєсовський підхід розглядає випадковість як внутрішню природну властивість реального об'єкта або процесу з урахуванням неперервних випадкових змін самого об'єкта як цілісної системи через вплив навколишнього середовища. Оцінками моделі вважають невипадкові статистичні характеристики, які досить близько апроксимують статистику випадкового параметра, тому під час практичного застосування дослідник працює з моделлю, що має детерміновані коефіцієнти. Імовірнісні властивості моделі використовуються для визначення похибки прогнозних розрахунків та аналізу чутливості моделі прогностичної динаміки.

Метою дослідження $є$ алгоритмізація процедури байєсовського оцінювання альтернативних рішень.

Виклад основного матеріалу. Процес моделювання, як правило, починається 3 виявлення емпіричної закономірності розвитку системи - об'єкта дослідження, аналізу зовнішніх та внутрішніх факторів, їх взаємозв'язків, тенденцій динамічної зміни навколишнього середовища. Наступним кроком $є$ теоретичне припущення про внутрішню логічну модель поведінки досліджуваного об'єкта, наявність типових зав'язків між структурними частинами та вплив навколишнього середовища, тобто станів природи. Розв'язання таких задач можна знайти шляхом перебору елементів множини альтернатив, кожна 3 яких 3 деякою ймовірністю може бути оптимальним рішенням $A=\left(a_{i}\right) ;(i=1 \div m)$, що залежать від випадкових станів природи $S=\left(s_{j}\right) ;(j=1 \div n)$ з відповідними оцінками - платежем $\left(\vartheta_{i j}\right)(i=1 \div m ; j=1 \div n)$.

Платіжну матрицю в задачі прийняття рішення для $m$ - альтернатив $3 n-$ станами природи можна привести в такій формі:

$$
\left(\vartheta_{i j}\right)=\left(\begin{array}{ccc}
\vartheta\left(a_{1}, s_{1}\right) & \cdots & \vartheta\left(a_{1}, s_{n}\right) \\
\vdots & \ddots & \vdots \\
\vartheta\left(a_{m}, s_{1}\right) & \cdots & \vartheta\left(a_{m}, s_{n}\right)
\end{array}\right) .
$$


Особливість прийняття рішення в умовах невизначеності полягає в тому, що ймовірнісний розподіл станів $s_{j} ;(j=1 \div n)$ або невідомий, або невизначений. Якщо розмір платежів $\vartheta_{i}, \quad(i=1 \div m ; j=1 \div n)$ для окремої альтернативи відомий або прогнозований, то об'єктом управління є стани природи $S_{j}=\left(s_{j}\right) ;(j=1 \div n)$. Якщо розподіл $\vartheta_{i j}$ для кожного значення $S=\left(s_{j}\right) ;(j=1 \div n)$ є випадковою величиною, то постає задача вибору апріорного розподілу, що задає початкове уявлення про поведінку параметрів моделі досліджуваної системи. Класичні методи статистичної оцінки використовують порівняльний аналіз теоретично можливих стохастичних моделей, що сформовані на основі наявних даних та характеристик, щодо відповідності цілям дослідження. На відміну від них, байєсовський підхід оцінює ймовірність відповідності моделі ще до отримання даних спостережень. Потім апріорний розподіл переглядається на основі вибіркових даних статистичних спостережень та відображається у вигляді апостеріорного розподілу параметрів, моделі. Таким чином, отримуємо сімейство пов'язаних розподілів.

Розглянемо випадкову величину $\mathrm{A}=\left(a_{i}\right) ;(i=1 \div m)$ ), що має деякий імовірнісний розподіл, визначений для кожного невідомого параметра $\mathrm{S}$, що належить до множини можливих значень $S=\left(s_{j}\right) ;(j=1 \div n)$.

Для заданого значення $A=a$ функція правдоподібності для кожного окремого значення $s=s_{j}$ задана у вигляді $p_{s}(a)$, тоді диференційна функція $є$ розподілом апріорних імовірностей $p(s), s \in S$, для яких виконується умова нормування $\sum_{j=1}^{n} p\left(s_{j}\right)=1$. Зв'язок між апріорними $p(s)$ та апостеріорними імовірностями $p_{a}(s), \stackrel{j=1}{p_{S}}(a)$ встановлює теорема Байєса

$$
\begin{aligned}
& p_{a}(s)=\frac{p_{S}(a) \cdot p(s)}{p(A)} \\
& p(A)=\sum_{i=1}^{m} p_{S}(a) \cdot p(s) .
\end{aligned}
$$

У припущені, що апріорний і апостеріорний розподіли належать до одного класу, множина можливих розв'язків апостеріорного розподілу буде замкненим багатокутником [5, с. 43].

Метод визначення розподілу апріорних імовірностей залежить від поставленої задачі. У задачах прогнозування тенденцій динаміки економічних показників як апріорних імовірностей можуть використовуватись експертні оцінки - суб'єктивні судження експертів щодо параметрів моделі [6, с. 125-133], а також ймовірнісна оцінка станів природи.

Якщо множина альтернатив $A=\left(a_{i}\right) ;(i=1 \div m)$ обмежена наявними або прогнозованими станами $S=\left(s_{j}\right) ;(j=1 \div n)$, то матриці $V=\left(\vartheta_{i j}\right)(i=1 \div m ; j=1 \div n)$ можна поставити у відповідність матрицю-вектор апостеріорних імовірностей, обчислену за формулою (3), що фактично визначає імовірнісну оцінку кожної альтернативи.

$$
K(A)=(p(A) \cdot V)=\left(\begin{array}{c}
p\left(a_{1}\right) \\
\vdots \\
p\left(a_{m}\right)
\end{array}\right) \cdot\left(\begin{array}{ccc}
\vartheta\left(a_{1}, s_{1}\right) & \cdots & \vartheta\left(a_{1}, s_{n}\right) \\
\vdots & \ddots & \vdots \\
\vartheta\left(a_{m}, s_{1}\right) & \cdots & \vartheta\left(a_{m}, s_{n}\right)
\end{array}\right)
$$

Добуток (4) може слугувати комплексним критерієм очікуваного значення. Таким чином, ми отримали модель кількісного оцінювання вибраної альтернативи 3 множини можливих альтернатив $A=\left(a_{i}\right) ;(i=1 \div m)$.

Задачу оптимізації прийняття рішення можна сформулювати як задачу знаходження екстремального значення комплексного критерія $K(A)$. 


$$
\hat{A}=F\{S, K(A)\} \rightarrow \text { exstr. }
$$

Вхідними даними такої задачі $є$ результат прогнозного моделювання поведінки досліджуваної системи та імовірнісних станів зовнішнього середовища.

Висновки. Можливість застосування байєсовського підходу не залежить від типу вибраної моделі. Метод Байєса імовірнісної оцінки альтернатив дає змогу побудувати досить просту та ефективну модель прийняття рішення для сформованої сукупності апріорних ознак - станів природи. Вибір методів формування розподілу апріорних імовірностей не обмежений лише статистичними алгоритмами, для економіко-математичних моделей найпростішим у реалізації $є$ метод експертних оцінок. Значною перевагою метода Байєса $є$ можливість корегування та уточнення початкових значень апріорних імовірностей у разі надходження нової інформації про об'єкт дослідження.

\section{Список використаних джерел:}

1. П’ятаков Е.М., Короленко О.В., Ходаков В.С., Дебела І.М., Соколов А.С. Особливості регіональних соціально-економічних систем України. Сучасні інформаційні та інноваційні технологіï на транспорті : матеріали XII міжнародної науково-практичної конференції MINTT-2020, м. Херсон, 27 травня 2020 р. Харків : ХДМА, 2020. С. 177-181.

2. Кирилов Ю.Є., Грановська В.Г., Алєщенко Л.О. Економічний механізм формування конкурентних переваг суб'єктів туристичної галузі. Економіка АПК. 2020. № 5. С. 45-55.

3. Дебела I.M. Формалізований алгоритм оптимізації процесу прийняття рішення в умовах стохастичної невизначеності. Інфраструктура ринку. 2021. № 55. С. 199-202.

4. Хэмди А., Таха. Введение в исследование операций : учебное пособие. 6-е изд. Москва : Вильямс, 2001. $912 \mathrm{c.}$

5. Бидюк В.В., Павлов А.С., Борисевич Л.Т. Применение метода Монте-Карло для марковских цепей к оцениванию регрессионных моделей. Кибернетика и вычислительная техника. 2009. Вып. 156. C. 40-57. URL: http://dspace.nbuv.gov.ua/handle/123456789/7631 (дата звернення: 21.08.2021).

6. Савчук В.П. Байесовские методы статистического оценивания. Надежность технических объектов. Москва : Наука, 1989. 328 с.

7. Лєпа Є.В., Дебела І.М. Прогнозування соціально-економічних процесів. Херсон, 2007. 182 с.

8. Балута В.И., Шульц Д.Н. Версия динамической стохастической модели общего равновесия для условий открытой экономики. Математическое моделирование. 2019. № 31:11. C. 117-131. URL: http://www.mathnet.ru/php/getFT.phtml?jrnid=mm\&paperid=4133\&what=fullt\&o ption_lang=rus (дата звернення: 21.08.2021).

9. Згуровський М.3. та ін. Байєсівські мережі в системах підтримки прийняття рішень. Київ : Едельвейс, 2015. 300 с.

10. Боярова К.І., Лозова О.Б., Бідюк П.І. Класифікація ризиків у страхуванні і байєсівський підхід до їх аналізу. Проблеми інформачійних технологій. 2013. № 13. С. 21-32.

11. Зельнер А. Байесовские методы в эконометрии. Москва : Статистика, 1980. 434 с.

12. Петров Э.Г., Крючковский В.В., Петров К.Э. Нормативная формализация процесса принятия решений в условиях многокритериальности и интервальной неопределенности. Проблеми інформаиійних технологій. 2014. № 15. C. 7-13. URL: http://openarchive.nure.ua/ handle/document/2373 (дата звернення: 21.08.2021).

13. Вітлінський В.В. Моделювання економіки : навчальний посібник. Київ : КНЕУ, 2003. 408 с.

14. Вітлінський В.В., Верченко П.Г. Аналіз, моделювання та управління економічним ризиком : навчальний посібник. Київ : КНЕУ, 2000. 292 с.

15. Сріна А.М. Статистичне моделювання та прогнозування : навчальний посібник. Київ : KHEУ, 2001. $170 \mathrm{c}$.

\section{References:}

1. Pyatakov E.M., Korolenko O.V., Khodakov V.E., Debela I.M., Sokolov A.E. (2020) Osoblyvosti reghionaljnykh socialjno-ekonomichnykh system Ukrajiny [Features of regional socio-economic systems of Ukraine]. Proceedings of the Modern information and innovative technologies in transport (in Ukrainian, Kherson, May 27, 2020), Kherson: Kherson State Maritime Academy, pp. 177-181. 
2. Kyrylov Yu.Ye., Hranovska V.H., Alieshchenko L.O. (2020) Ekonomichnyi mekhanizm formuvannia konkurentnykh perevah subiektiv turystychnoi haluzi [Economic mechanism of formation of competitive advantages of subjects of tourist branch]. Ekonomika APK, no. 5, pp. 45-55.

3. Debela I.M. (2021) Formalizovanyj alghorytm optymizaciji procesu pryjnjattja rishennja $\mathrm{v}$ umovakh stokhastychnoji nevyznachenosti [A formalized algorithm for optimizing the decision-making process in conditions of stochastic uncertainty]. Market infrastructure, vol. 55, pp. 199-202.

4. Hamdy A., Taha (2001) Vvedenye v yssledovanye operatsyi [Introduction to operations research]. Moscow: Williams. (in Russian)

5. Bidyuk V.V., Pavlov A.S., Borisevich L.T. (2009) Primenenie metoda Monte-Karlo dlya markovskikh tsepey $\mathrm{k}$ otsenivaniyu regressionnykh modeley [Application of the Monte Carlo method for Markov chains to the estimation of regression models]. Cybernetics and Computing, vol. 156, pp. 40-57.

6. Savchuk V.P. (1989) Bayesovskie metody statisticheskogo otsenivaniya: Nadezhnost' tekhnicheskikh ob'ektov [Bayesian Statistical Estimation Methods: Reliability of Technical Objects]. Moscow: Science. (in Russian)

7. Lepa E.V., Debela I.M. (2007) Proghnozuvannja socialjno-ekonomichnykh procesiv [Forecasting of socio-economic processes]. Kherson: Kherson city printing house. (in Ukrainian)

8. Baluta V.I., Shultz D.N. (2019) Versiya dinamicheskoy stokhasticheskoy modeli obshchego ravnovesiya dlya usloviy otkrytoy ekonomiki [A version of a dynamic stochastic general equilibrium model for an open economy]. Math modeling, vol. 31:11, pp. 117-131.

9. Zgurovsky M.Z., Bidyuk P.I., Terentyev O.M., Prosyankina-Zharova T.I. (2015) Bajjesivsjki merezhi v systemakh pidtrymky pryjnjattja rishenj [Bayesian networks in decision support systems]. Kyiv: Edelweiss. (in Ukrainian)

10. Boyarova K.I., Lozova O.B., Bidyuk P.I. (2013) Klasyfikacija ryzykiv u strakhuvanni i bajjesivsjkyj pidkhid do jikh analizu [Classification of risks in insurance and Bayesian approach to their analysis]. Problems of information technologies, no. 13, pp. 21-31.

11. Zellner A. (1980) Bayesovskie metody v ekonometrii [Bayesian methods in econometrics]. Moscow: Statistics. (in Russian)

12. Petrov E.G., Kryuchkovsky V.V., Petrov K.E. (2014) Normativnaya formalizatsiya protsessa prinyatiya resheniy v usloviyakh mnogokriterial'nosti i interval'noy neopredelennosti [Normative formalization of the decision-making process in conditions of multi-criteria and interval uncertainty]. Problems of information technologies, no. 15, pp. 7-13.

13. Vitlinsky V.V. (2003) Modeljuvannja ekonomiky [Modeling of economy]. Kyiv: KNEU. (in Ukrainian)

14. Vitlinsky V.V., Verchenko P.G. (2000) Analiz, modeliuvannia ta upravlinnia ekonomichnym ryzykom [Analysis, modeling and management of economic risk]. Kyiv: KNEU. (in Ukrainian)

15. Erina A.M. (2001) Statystychne modeljuvannja ta proghnozuvannja [Statistical modeling and forecasting]. Kyiv: KNEU. (in Ukrainian) 